\title{
Bimbingan Teknis Pengawasan Koperasi Se-Kabupaten Bengkayang Tahun 2019: Manajemen Pengawasan Koperasi
}

\section{Technical Guidance for Cooperative Supervision in Bengkayang Regency in 2019: Cooperative Supervision Management}

Sabinus Beni*
Blasius Manggu
Department of Entrepreneurship,
Sekolah Tinggi Ilmu Manajemen
Shanti Bhuana, Bengkayang, West
Kalimantan, Indonesia
*email: beni@shantibhuana.ac.id
Kata Kunci
Koperasi
Manajemen Koperasi
Pengawasan Koperasi
Keywords:
Cooperative
Cooperative management
Cooperative Supervision
Received: September 2019
Accepted: November 2019
Published: December 2019

\begin{abstract}
Abstrak
Pelaksanaan kegiatan Bimtek Pengawasan Koperasi Se-Kabupaten Bengkayang dilakukan Oleh Dinas Koperasi, UKM, Tenaga Kerja, dan Transmigrasi Kabupaten Bengkayang dalam menyikapi kondisi 189 Koperasi di Kabupaten Bengkayang dengan 125 Koperasi Aktif dan hanya 24 Koperasi yang telah melaksanakan Rapat Anggota Tahunan. Tujuan dari kegiatan ini adalah untuk memberikan bimbingan secara teknis kepada 30 orang pengawas koperasi untuk dapat memaksimalkan fungsi pengawasan agar 125 Koperasi aktif melaksanakan Rapat Anggota Tahunan. Adapun metode pelaksanaan kegiatan dimulai dengan presentasi materi dan tanya jawab. Secara umum peserta memahami tentang materi manajemen pengawasan koperasi serta berkomitmen melaksanakannya terutama dengan mendorong masing-masing pengurus dan karyawan koperasi untuk melaksanakan Rapat Anggota Tahuan secara rutin setiap tahun.
\end{abstract}

\begin{abstract}
The implementation of the Technical Guidance for Supervision of Cooperative Supervision of Bengkayang Regency is carried out by the Department of Cooperatives, Small and Medium Enterprises, Labor, and Transmigration of Bengkayang Regency in responding to the conditions of 189 Cooperatives in Bengkayang Regency with 125 Active Cooperatives and only 24 Cooperatives that have conducted Annual Member Meetings. The purpose of this activity is to provide technical guidance to 30 cooperative supervisors to be able to maximize the oversight function so that 125 cooperatives actively carry out the Annual Member Meeting. The method of implementing the activity begins with the presentation of material and questions and answers. In general, participants understood about cooperative supervision management material and committed to implementing it, especially by encouraging each cooperative's management and employees to hold annual Member Meetings regularly.
\end{abstract}

\section{PENDAHULUAN}

Koperasi adalah organisasi ekonomi yang dimiliki dan dioperasikan oleh individu untuk kebaikan bersama. Kegiatan berbasis koperasi didasarkan pada prinsip gerakan ekonomi rakyat berdasarkan prinsip keluarga (Erman, 2017; Sastrawidjaja \& Adam, 2015). Berbeda dengan bentuk usaha lainnya, koperasi memiliki ciri khas dalam hal pengelolaannya. Di Indonesia sendiri, tata kelola dan regulasi terkait koperasi berada dalam wewenang Kementerian Koperasi dan Usaha Kecil dan Menengah (Cahyaningrum, 2017).

Kegiatan Bimbingan Teknis (Bimtek) Pengawasan Koperasi Se-Kabupaten Bengkayang Tahun 2019 dilaksanakan tanggal 22 Agustus tahun 2019 di Aula Penginapan Tuah Raya Jalan Guna Baru Trans Rangkang Bengkayang yang dilaksanakan oleh Dinas Koperasi, Usaha Kecil dan Menengah (UKM), Tenaga 
Kerja, dan Transmigrasi Kabupaten Bengkayang. Kegiatan ini bertujuan untuk mengangkat dan memotivasi Koperasi yang ada di Kabupaten Bengkayang untuk terus dapat berpartisipasi dalam meningkatkan taraf hidup masyarakat melalui koperasi yang diawali dengan tertib administrasi serta melaksanakan Rapat Anggota Tahunan (RAT) secara kontinyu. Data Koperasi di Kabupaten Bengkayang sebanyak 189 Koperasi. Dari 189 jumlah koperasi yang ada di Kabupaten Bengkayang sebanyak 125 koperasi yang aktif dan baru 24 Koperasi yang melakukan RAT (berdasarkan pemaparan Plt. Kepala Dinas Koperasi, UKM, Tenaga Kerja dan Transmigrasi Kabupaten Bengkayang, Bapak Heru Pujiono. Peserta yang hadir sebanyak 30 orang dari unsur Pengawas masing-masing perwakilan Koperasi yang diundang oleh Dinas Koperasi, UKM, Tenaga Kerja, dan Transmigrasi Kabupaten Bengkayang serta 3 orang Petugas Penyuluh Koperasi Lapangan. Adapun tujuan dari kegiatan pengabdian ini adalah memberikan bimbingan secara teknis kepada 30 orang pengawas koperasi untuk dapat memaksimalkan fungsi pengawasan agar 125 Koperasi aktif melaksanakan Rapat Anggota Tahunan secara rutin.

\section{METODOLOGI}

Alat dan bahan yang digunakan dalam dalam kegiatan Bimtek ini adalah Materi Power Point (PPT) dengan Topik: "Manajemen Pengawasan Koperasi". Materi disusun berdasarkan undangan yang diterima oleh bagian Pusat Registrasi dan Operasional Akademik (PROA) Sekolah Tinggi Ilmu Manajemen Shanti Bhuana pada tanggal 21 Agustus 2019 dari Dinas Koperasi, UKM, Tenaga Kerja, dan Transmigrasi Kabupaten Bengkayang tentang Permohonan Narasumber Bimbingan Teknis Pengawasan Koperasi Se-Kabupaten Bengkayang Tahun 2019 di Aula Tuah Raya Jalan Guna
Baru Trans Rangkang Kelurahan Sebalo Kecamatan Bengkayang.

Metode pelaksanaan dilakukan dengan susunan kegiatan sebagai berikut:

1. Pembuatan Materi Presentasi

2. Cetak materi untuk peserta Bimtek oleh Panitia

3. Registrasi Peserta (Sebanyak 30 orang Pengawas Koperasi dan tiga orang Petugas Penyuluh Koperasi Lapangan)

4. Pembukaan Kegiatan diawali dengan Doa dan Sambutan Kepala Dinas Koperasi, UKM, Tenaga Kerja, dan Transmigrasi Kabupaten Bengkayang oleh Bapak Heru Pujiono.

5. Presentasi materi Manajemen Pengawasan Koperasi selama \pm 2 jam (pukul 09.45 sampai dengan pukul 12.15 WIB).

6. Tanya Jawab dan dilanjutkan oleh materi lain dari Narasumber dan topik yang berbeda

\section{HASIL DAN PEMBAHASAN}

Materi Bimtek diambil dari buku Credit Union Series 3Auditor's Manual for ACCESS yang dialihbahasa oleh Munaldus (2009) dan diterbitkan oleh Association of Asian Confederation of Credit Unions (ACCU) yang berkaitan dengan Diagram Proses Audit ACCESS, Perspektif Keuangan, Perspektif Proses Bisnis Internal, dan Perspektif Pembelajaran dan Pertumbuhan Koperasi. Materi juga diambil dari Peraturan Menteri Negara Koperasi dan UKM Nomor 19/Per/M.KUKM/XI/2008 tentang Pedoman Pelaksanaan Kegiatan Usaha Simpan Pinjam oleh Koperasi. Selain itu, materi terkait Perkreditan, Prospek dan Produk Simpanan diambil dari Buku Pembangunan Manusia Melalui Pendidikan Dasar Credit Union (Beni, 2017). Tampilan Power Point yang digunakan disajikan pada Gambar 1. 


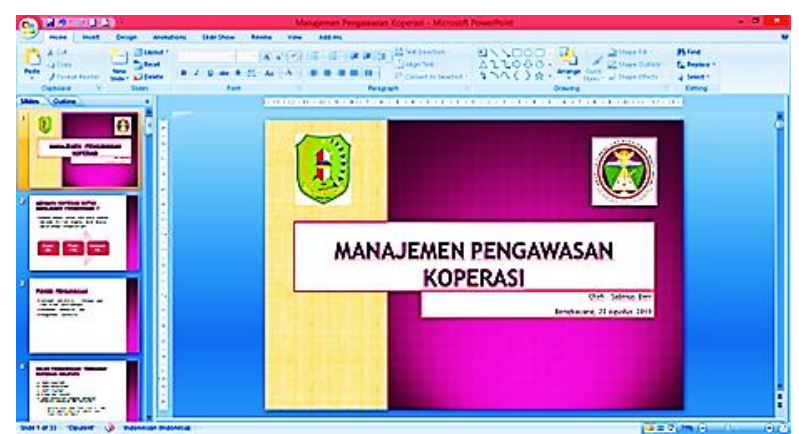

Gambar 1. Power Point Materi Bimtek

Mengawali materi presentasi tentang Manajemen Pengawasan Koperasi, dilakukan refleksi pemaparan Plt. Kepala Dinaas Koperasi, UKM, Tenaga Kerja, dan Transmigrasi Kabupaten Bengkayang bahwa terdapat 189 Koperasi yang ada di Kabupaten Bengkayang hanya 124 Koperasi aktif dan hanya 24 Koperasi yang telah dan pernah melaksanakan RAT. Dokumentasi kegiatan Bimtek disajikan pada Gambar 2. Adapun materi pokok yang disampaikan pada kegiatan Bimtek ini adalah sebagai berikut:

1. Pengertian Manajemen Pengawasan,

2. Mengapa Koperasi Butuh Manajemen Pengawasan,

3. Fungsi Pengawasan,

4. Objek Pengawasan: Aspek Organisasi, Aspek Pengelolaan, Aspek Keuangan, Produk dan Layanan, Aspek Pembinaan Anggota, Pengurus, Pengawas dan Karyawan.

5. Refleksi Kasus (Uganda, 2004 dan Credit Union di Inggris, 2008),

6. Implementasi Manajemen Pengawasan melalui Pemetaan Terhadap Risiko: Risiko Kredit, Risiko Pasar (pasar dan suku bunga), Risiko Operasi.

7. Risiko vs Masalah,

8. Risiko vs Ketidakpastian,

9. Peran Manajemen Risiko Dalam Koperasi,

10. Proses Manajemen Pengawasan,

11. Identifikasi dan Pengukuran Risiko,

12. Praktik Membuat Pengukuran Probabilitas Risiko secara Kualitatif, Pengukuran Dampak Risiko Secara
Kualitatif, dan Penilaian Tingkat Risiko serta Pencegahan, Penanganan, Monev dan Pelaporan (Beni, 2016; Mega, 2016; Dharma et al., 2014; Carollina \& Sutarta, 2014).

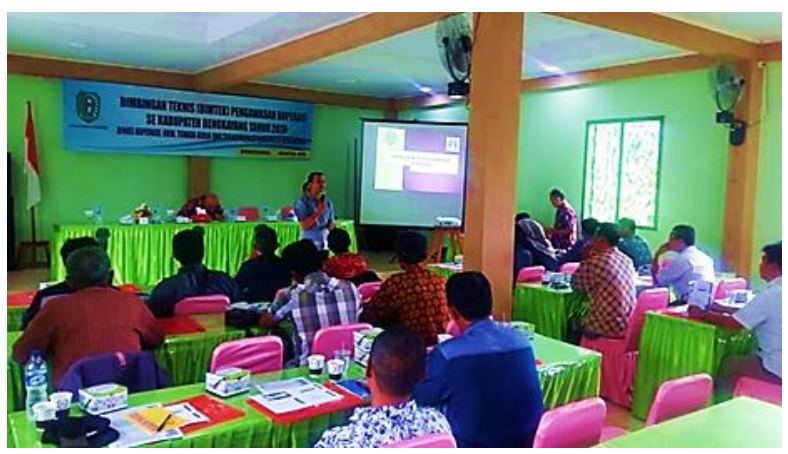

Gambar 2. Suasana Kegiatan Bimtek

Materi disampaikan diawali dengan perkenalan antara narasumber dengan peserta bimtek. Peserta bimtek berjumlah 30 orang unsur pengawas dari berbagai koperasi di Kabupaten Bengkayang antara lain: Koperasi Simpan Pinjam, Koperasi Guru, KUD, Koperasi Jasa, Koperasi Pertanian, dan Koperasi Produksi. Selain unsur pengawas koperasi, bimtek juga diikuti oleh tiga orang Petugas Penyuluh Koperasi Lapangan (PPKL) Kabupaten Bengkayang.

Penyampaian materi dimulai pukul 09.55 WIB, penyampaian materi dilakukan secara santai dan suasana yang penuh antusias. Peserta secara santai dan antusias mengikuti serta menyimak materi yang disampaikan disertai beberapa joke yang membuat suasana semakin akrab dan tentunya tidak bosan. Penyampaian materi berakhir hingga pukul 11.50 WIB dilanjutkan dengan sesi tanya jawab. Beberapa pertanyaan yang muncul antara lain:

1. Bagaimana memulai melakukan pengawasan,

2. Apa yang harus disiapkan,

3. Bagaimana menghitung rasio kredit beredar,

4. Bagaimana cara mengajukan proposal bantuan dana melalui Lembaga Pengelolaan Dana Bergulir (LPDB) Kementerian Koperasi secara online, 
5. Bagaimana cara menjadi pengawas koperasi yang baik.

Pertanyaan-pertanyaan diatas dijawab satu persatu secara singkat oleh pemateri dikarenakan waktu yang tidak memungkinkan untuk menjawab secara detail. Namun dari jawaban yang diberikan, peserta merasa cukup terbantu dan sessi materi Manajemen Pengawasan Koperasi diakhiri hingga pukul 12.15 WIB dilajutkan dengan Istirahat siang dan setelah istrahat siang dilanjutkan dengan materi lainnya oleh narasumber yang berbeda hingga pukul 15.30 WIB dan diakhiri dengan Photo Bersma serta pemberian sertifikat sebagai narasumber oleh Panitia (Dinas Koperasi, UKM, Tenaga Kerja, dan Transmigrasi Kabupaten Bengkayang).

Rencana tindak lanjut dari kegiatan Bimbingan Teknis Pengawasan Koperasi Se Kabupaten Begkayang Tahun 2019 ini akan dilakukan Monitoring dan Evaluasi pada Tahun 2020 dengan melihat data Koperasi aktif (124 koperasi) yang telah melaksanakan Rapat Anggota Tahunan Tahun Buku 2019. Akan dilakukan survey secara acak pada salah satu koperasi untuk melihat efektifitas dan penerapan manajemen pengawasan yang dilakukan oleh pengawas koparasi. Hasil monev tersebut dapat dilakukan kegiatn pendampingan maupun penelitian lanjutan untuk meningkatkan volume usaha koperasi di Kabupaten Bengkayang, terutama tingkat ketaatan dalam melaksanakan Rapat Anggota Tahunan secara terus-menerus serta menerapkan budaya manajemen pengawasan untuk mencegah ketidakaktifan koperasi.

\section{KESIMPULAN}

Dari Kegiatan Bimtek ini, dapat kami tarik Kesimpulan: Peserta Bimtek sangat antusias mengikuti kegiatan bimtek untuk perbaikan Manajemen Pengawasan Koperasi dibuktikan dengan banyaknya pertanyaan yang disampaikan pada saat sesi tanya jawab terkait dengan penyempurnaan Manajemen Pengawasan Koperasi.

\section{UCAPAN TERIMA KASIH}

Kegiatan Bimtek Koperasi dapat berjalan dengan baik berkat dukungan banyak pihak, antara lain Dinas Koperasi, UKM, Tenaga Kerja, dan Transmigrasi Kabupaten Bengkayang, selaku panitia yang telah mengundang kami sebagai narasumber; 30 orang peserta yang berasal dari unsure Pengawas beberapa Koperasi dan 3 orang petugas PPKL; Penginapan Tuah Raya, yang telah menyediakan tempat dilaksanakannya kegiatan Bimtek; Bapak Dokman Marulitua Situmorang sebagai pemberi informasi terkait undangan dari panitia dan materi yang akan disampaikan; Bapak Blasius Manggu yang ikut membantu mensukseskan kegiatan terutama dalam bidang Dokumentasi Kegiatan; serta Kampus STIMShanti Bhuana, yang mendukung penuh kegiatan Bimtek sebagai kegiatan Pengabdian Masyarakat kami melalui penerbitan Surat Tugas sebagai Narasumber.

\section{REFERENSI}

Beni, S. 2017. Pembangunan Manusia Melalui Pendidikan Dasar Credit Union. Jakarta: Mer-C Publishing.

Beni, S. 2016. Pengaruh Jumlah Simpanan dan Tunggakan Kredit Terhada Kesejahteraan Anggota Koperasi Kredit (Studi Kasus: Credit Union Lantang Tipo). In Prosiding Seminar Nasional VIII 2016 Fakultas Ekonomi Universitas Terbuka. Tangerang: Universitas Terbuka.

Cahyaningrum, D. 2017. Bentuk Badan Hukum Koperasi Untuk Menjalankan Kegiatan Usaha Perbankan. Negara Hukum: Membangun Hukum Untuk Keadilan dan Kesejahteraan. 8(1):130. https://doi.org/10.22212/jnh.v8i1.935

Carollina, M., Sutarta, A.E. 2014. Peranan Credit Union Sebagai Lembaga Pembiayaan Mikro Studi Kasus: Pada Usaha Umkm Di Desa Tumbang 
Manggo Kecamatan Sanaman Mantikei, Kabupaten Katingan, Provinsi Kalimantan Tengah Tahun 2013. Modus. 26(2):157-172. https://doi.org/10.24002/modus.v26i2.586

Dharma, H.G., Rudy, D.G., Purwanti, N.P. 2014. Peran Satuan Tugas Pengawasan Dinas Koperasi Provinsi Bali Dalam Mengawasi Koperasi Simpan Pinjam. Kertha Semaya: Journal Ilmu Hukum. 2(3):1-5.

Erman. 2017. Standar Kompetensi Pengelola Koperasi Simpan Pinjam Syariah Di BMT Taqwa Muhammadiyah Padang. Maqdis: Jurnal Kajian Ekonomi Islam. 2(2):193-203. http://dx.doi.org/10.15548/maqdis.v2i2.128

Mega, U.S.K. 2016. Peran Knowladge Sharing Dalam Memperkuat Pengaruh Kompetensi dan Rotasi Kerja Untuk Meningkatkan Kinerja SDM (Studi Pada Dinas Koperasi dan UMKM Provinsi Jawa Tengah). In Prosiding Seminar Nasional VIII 2016 Fakultas Ekonomi Universitas Terbuka. Tangerang: Universitas Terbuka.

Munaldus. 2009. Credit Union Series 3-Auditor's Manual for ACCESS. Association of Asian Confederation of Credit Union.

Pemerintah Republik Indonesia. 2008. Peraturan Menteri Koperasi Republik Indonesia Nomor 19/Per/M.KUKM/XI/2008 Tentang Pedoman Pelaksanaan Kegiatan Usaha Simpan Pinjam Oleh Koperasi

Sastrawidjaja, H.M.S., Adam, R.C. 2015. Langkah Menuju Konglomerasi Koperasi Di Indonesia. PADJADJARAN: Jurnal Ilmu Hukum (Journal of Law). 2(2):209-231.

https://doi.org/10.22304/pjih.v2n2.a1 